This is a self-archived version of an original article. This version may differ from the original in pagination and typographic details.

Author(s): Heilmann, Andreas; Hicks, Jamie; Vasko, Petra; Goicoechea, Jose; Aldridge, Simon

Title: Carbon Monoxide Activation by a Molecular Aluminium Imide : C-O Bond Cleavage and C-C Bond Formation

Year: 2020

Version: Accepted version (Final draft)

Copyright: @ 2020 WILEY-VCH Verlag GmbH \& Co. KGaA, Weinheim

Rights: In Copyright

Rights url: http://rightsstatements.org/page/InC/1.0/?language=en

Please cite the original version:

Heilmann, A., Hicks, J., Vasko, P., Goicoechea, J., \& Aldridge, S. (2020). Carbon Monoxide Activation by a Molecular Aluminium Imide : C-O Bond Cleavage and C-C Bond Formation. Angewandte Chemie, 591(12), 4897-4901. https://doi.org/10.1002/anie.201916073 


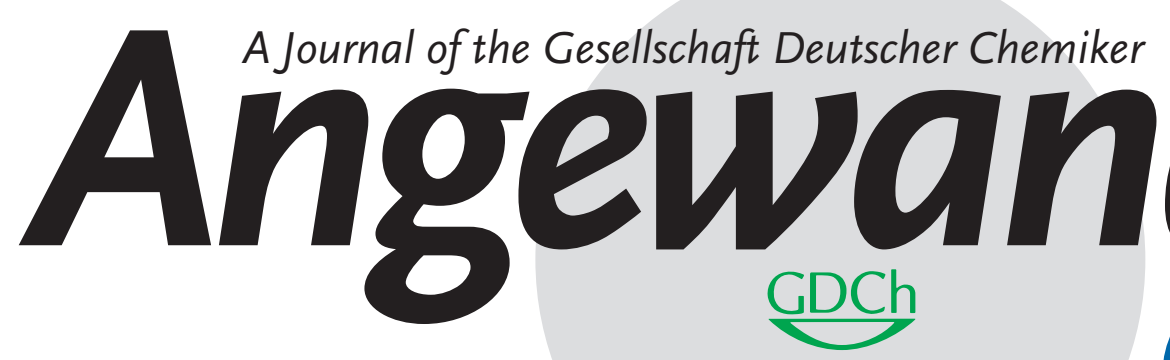

International Edition

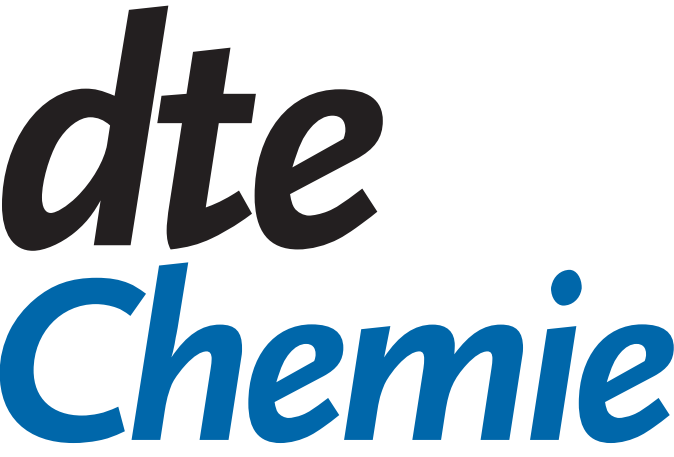

www.angewandte.org

\section{Accepted Article}

Title: Carbon Monoxide Activation by a Molecular Aluminium Imide: C$\mathrm{O}$ Bond Cleavage and $\mathrm{C}-\mathrm{C}$ Bond Formation

Authors: Andreas Heilmann, Jamie Hicks, Petra Vasko, Jose Goicoechea, and Simon Aldridge

This manuscript has been accepted after peer review and appears as an Accepted Article online prior to editing, proofing, and formal publication of the final Version of Record (VoR). This work is currently citable by using the Digital Object Identifier (DOI) given below. The VoR will be published online in Early View as soon as possible and may be different to this Accepted Article as a result of editing. Readers should obtain the VoR from the journal website shown below when it is published to ensure accuracy of information. The authors are responsible for the content of this Accepted Article.

To be cited as: Angew. Chem. Int. Ed. 10.1002/anie.201916073

Angew. Chem. 10.1002/ange.201916073

Link to VoR: http://dx.doi.org/10.1002/anie.201916073

http://dx.doi.org/10.1002/ange.201916073 
WILEY-VCH

\title{
Carbon Monoxide Activation by a Molecular Aluminium Imide: C-O Bond Cleavage and C-C Bond Formation
}

\author{
Andreas Heilmann, ${ }^{[a]}$ Jamie Hicks, ${ }^{[a]}$ Petra Vasko, ${ }^{[a, b]}$ Jose M. Goicoechea ${ }^{*[a]}$ and Simon Aldridge ${ }^{*[a]}$
}

\begin{abstract}
Anionic molecular imide complexes of aluminium are accessible via a rational synthetic approach involving the reactions of organo azides with a potassium aluminyl reagent. In the case of $\mathrm{K}_{2}$ [(NON)AI(NDipp) $]_{2}$ (NON $=4,5$-bis(2,6-diisopropylanilido)-2,7-ditert-butyl-9,9-dimethyl-xanthene; Dipp $=2,6$-diisopropylphenyl) structural characterization by X-ray crystallography reveals a short Al$\mathrm{N}$ distance, which is thought to be due primarily to the low coordinate nature of the nitrogen centre. The Al-N unit is highly polar, and capable of the activation of relatively inert chemical bonds, such as those found in dihydrogen and carbon monoxide. In the case of $\mathrm{CO}$, uptake of two molecules of the substrate leads to $\mathrm{C}-\mathrm{C}$ coupling and $\mathrm{C} \equiv \mathrm{O}$ bond cleavage. Thermodynamically, this is driven - at least in part - by Al-O bond formation. Mechanistically, a combination of quantum chemical and experimental observations suggest that the reaction proceeds via exchange of the NR and $O$ substituents through intermediates featuring an aluminium-bound isocyanate fragment.
\end{abstract}

C-C coupling and $\mathrm{C}-\mathrm{O}$ bond cleavage of carbon monoxide are processes of great interest both from a fundamental perspective and because of their relevance to the formation of $\mathrm{C}-\mathrm{C}$ homogated products via Fischer-Tropsch chemistry. ${ }^{[1]}$ Reductive coupling of $\mathrm{CO}$ molecules to give systems of the type $\left[(\mathrm{CO})_{n}\right]^{2-}$ via $\mathrm{C}-\mathrm{C}$ bond formation has been accomplished by a range of metal systems from across the Periodic Table, including a number of $p$-block compounds. ${ }^{[2-6]}$ These include reactive low-valent systems featuring boron, ${ }^{[5 a]}$ silicon ${ }^{[5 e]}$ or germanium centres. ${ }^{[5 b]}$ The accomplishment of $\mathrm{CO}$ bond cleavage by $p$-block systems is also very rare, although recent examples have been reported exploiting a frustrated Lewis pair (FLP) approach. ${ }^{[6]}$ Main group systems which can accomplish both $\mathrm{C}-\mathrm{O}$ cleavage and $\mathrm{C}-\mathrm{C}$ coupling are almost unknown - with prominent recent examples from the groups of Scheschekitz and Driess utilising low valent silicon to generate alkyne/oxide or ketene/oxide fragments from two equivalents of $\mathrm{CO} .^{[7]}$

We have recently been interested in the development of highly reactive aluminium species for the activation of kinetically challenging substrates, such as those containing $\mathrm{H}-\mathrm{H}, \mathrm{C}-\mathrm{H}$ and $\mathrm{C}-\mathrm{C}$ bonds. ${ }^{[8]}$ Within this sphere, the development of well-defined molecular species containing highly polar Al-E bonds has been shown to offer a route to the activation of small molecules in 1,2-

[a] Mr. A. Heilmann, Dr. J. Hicks, Dr. P. Vasko, Prof. J. Goicoechea Prof. S. Aldridge

Inorganic Chemistry Laboratory, Department of Chemistry, University of Oxford, South Parks Road, Oxford, OX1 3QR, UK E-mail: simon.aldridge@chem.ox.ac.uk;

jose.goicoechea@chem.ox.ac.uk

[b] Dr. P. Vasko

Department of Chemistry, Nanoscience Center,

University of Jyväskylä, P. O. Box 35, Jyväskylä, Finland, FI-40014

Supporting information for this article is given via a link at the end of the document. Structural data has been deposited with the CCDC (ref: 1972052-1972057) fashion. Thus, a well-defined molecular aluminium oxide system (I, Figure 1) has been shown to activate $\mathrm{H}_{2}$ in a co-operative (FLPlike) manner exploiting the Lewis acidic nature of the aluminium centre and the Lewis basic oxide ligand, to give the corresponding aluminium hydroxide hydride. ${ }^{[8 d]}$ This oxide species is highly reactive and we therefore sought to target related imide species containing a discrete [AINR] function, which (on the basis of a less polarized and more sterically protected Al-E bond) might be expected to offer greater control of reactivity. Structurally characterized terminal aluminium imides of this type are rare (e.g. III), ${ }^{\left[{ }^{9]}\right.}$ and we therefore sought a versatile synthetic approach to such compounds in order to explore their patterns of reactivity with $\mathrm{H}_{2}$ and $\mathrm{CO}$ (as examples of small molecules which are known to react with FLPs). ${ }^{[10]}$ These studies are reported here.

A potential strategy for the synthesis of discrete molecular imide species involves the reaction of an organo azide with an $\mathrm{Al}(\mathrm{I})$ complex via elimination of $\mathrm{N}_{2}$. This strategy has previously been employed by Power, Roesky and co-workers (e.g. for IV and $\mathbf{V}$, Scheme 1), ${ }^{[11]}$ and a related approach has been reported by Coles and co-workers for the synthesis of an indium imide complex $(\mathbf{V I}) .{ }^{[12]}$ Similar chemistry has also been employed both by ourselves and by Anker and Coles for the synthesis of molecular aluminium oxide species via the reaction of anionic $\mathrm{Al}(\mathrm{I})$ precursors with $\mathrm{N}_{2} \mathrm{O}$ (I and II). ${ }^{[8 d, 13]}$
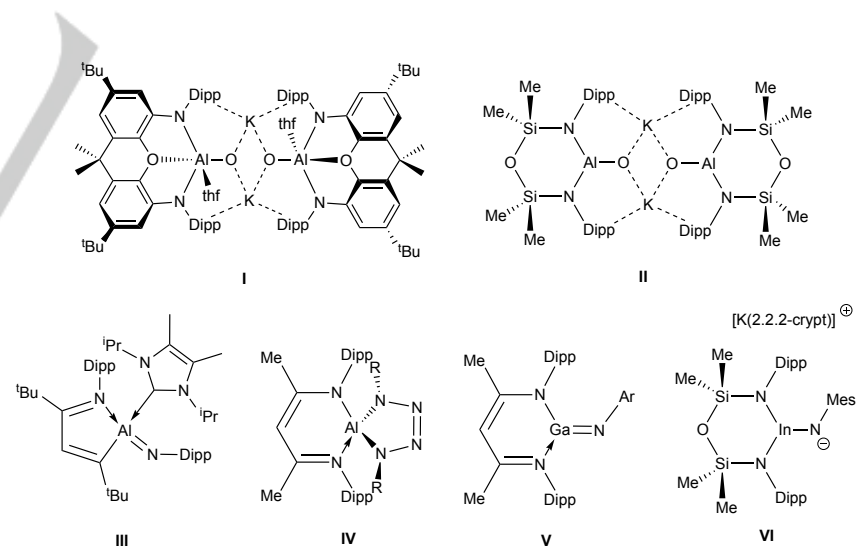

Figure 1. Group 13 metal imide, oxide and related species of relevance to the current study.

With the idea of extending this approach to anionic aluminium imide species, we therefore probed the reactivity of the potassium aluminyl complex 1 towards trimethylsilylazide, $\mathrm{Me}_{3} \mathrm{SiN}_{3}$. However, the reaction of 1 with excess azide in toluene results instead in the formation of the (crystallographically characterized) tetrazene complex, $\mathbf{2}$, in similar fashion to the formation of a cishyponitrite complex from 1 and excess $\mathrm{N}_{2} \mathrm{O}$ in the same solvent (Scheme 2 and ESI). ${ }^{\left[{ }^{[d]}\right.}$ Reasoning that such a transformation proceeds via transient formation of the corresponding trimethylsilyl-substituted imide complex (which then traps a 
second equivalent of $\mathrm{Me}_{3} \mathrm{SiN}_{3}$ via cycloaddition), ${ }^{[11 \mathrm{~b}]}$ we examined the analogous reaction with stoichiometric azide. In this case, the product isolated from toluene (3, Scheme 1 and ESI) is derived from activation of the benzylic $\mathrm{C}-\mathrm{H}$ bond of the solvent across the Al-N bond of the target imide. Attempts to use less acidic solvents (e.g. benzene) resulted in the formation of alternative products thought to result from C-H activation of a pendant Dipp substituent. While formation of $\mathbf{2}$ and $\mathbf{3}$ provides evidence for the in situ generation of an aluminium imide species from 1 and an azide reagent, alternative organo substituents were sought in order to allow structural authentication of such a complex.

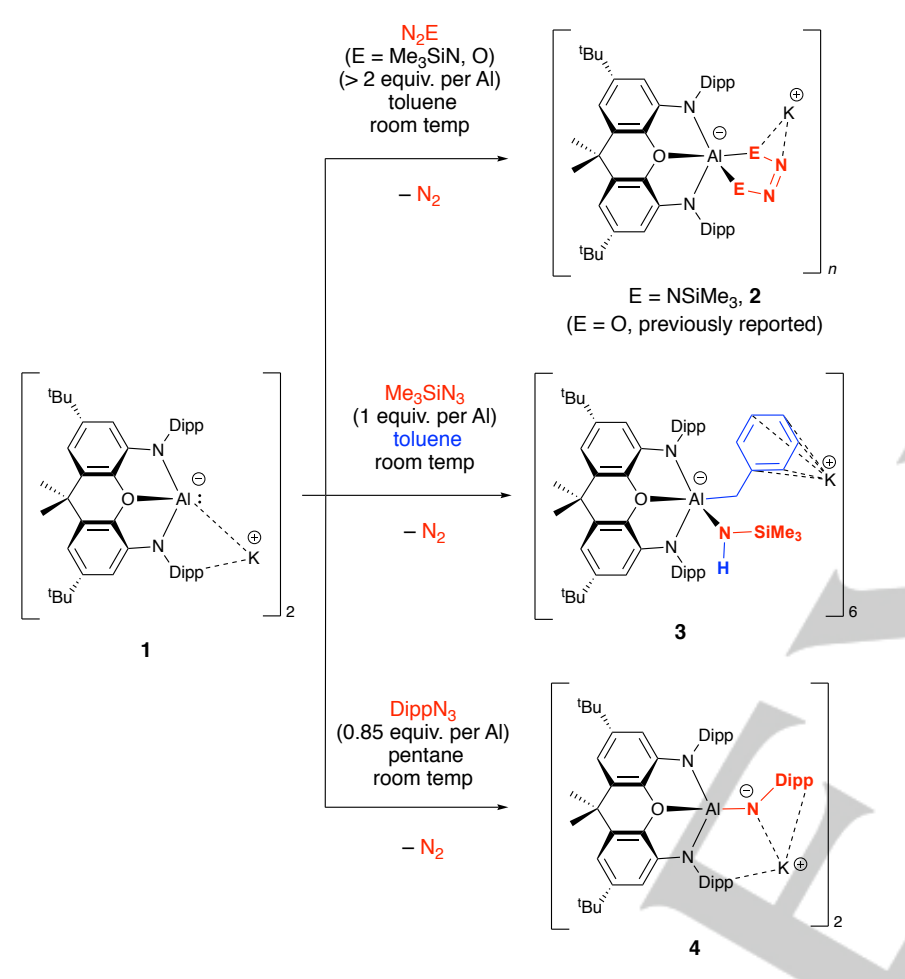

Scheme 1. Reactivity of potassium aluminyl complex 1 towards $\mathrm{Me}_{3} \mathrm{SiN}_{3}$, Dipp $\mathrm{N}_{3}$ and $\mathrm{N}_{2} \mathrm{O}$ (Dipp $=2,6-{ }^{-} \mathrm{Pr}_{2} \mathrm{C}_{6} \mathrm{H}_{3}$ ).

In order to generate an isolable imide complex, we turned to azide reagents bearing more sterically bulky (and less $\sigma$-donating) substituents. Accordingly, the reaction of 1 with 2,6-diisopropylphenylazide $\left(\mathrm{DippN}_{3}\right)$ proceeds smoothly to afford imide complex $\mathbf{4}$ in good isolated yields (up to $90 \%$ ). $\mathbf{4}$ has been characterized by standard spectroscopic and analytical techniques and by X-ray crystallography (Figure 2). The solid-state structure comprises two anionic [(NON)Al(NDipp)] units bridged by $\mathrm{K}^{+}$counter ions, yielding a centrosymmetric dimer. The $\mathrm{Al}(1)-\mathrm{N}(3)$ and $\mathrm{N}(3)-\mathrm{C}(48)$ bond lengths [1.723(2) and 1.346(4) $\AA$, respectively] are both very short, a finding which might indicate some degree of multiple bond character. DFT calculations, however, imply that this is unlikely to be the case for the Al- $\mathrm{N}$ bond (see below) and that the short Al-N separation is primarily a function of the low coordination number at $\mathrm{N}(3)$. Consistently, the $\mathrm{Al}(1)-\mathrm{N}(3)-\mathrm{C}(48)$ angle is found to be relatively wide $\left[146.4(2)^{\circ}\right]$ and the $\mathrm{N}(3) \cdots \mathrm{K}(1)$ contact $[2.740(2) \AA]$ is only just within the sum of the respective covalent radii $(2.74$ A). ${ }^{[14]}$
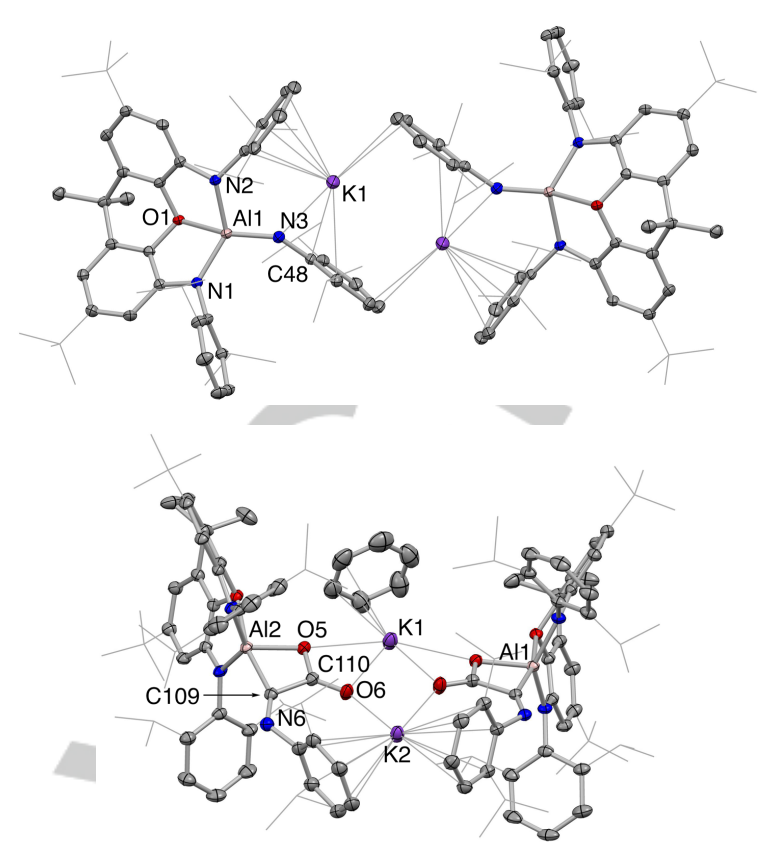

Figure 2. Molecular structures of $\mathbf{4}$ (top) and $\mathbf{6}$ (bottom) as determined by X-ray crystallography. Thermal ellipsoids set at the $35 \%$ probability level. Most solvate molecules and most hydrogen atoms omitted, and selected groups shown in wireframe format for clarity. Selected bond lengths $(\AA)$ and angles $\left({ }^{\circ}\right)$ for $4: \mathrm{Al}(1)$ $\mathrm{O}$ (1) 2.043(2), Al(1)-N(1) 1.896(2), Al(1)-N(2) 1.892(3), Al(1)-N(3) 1.723(2), $\mathrm{N}(3)-\mathrm{C}(48)$ 1.346(4), N(3)-K(1) 2.740(2); for 6: Al2-O5 1.306(4), Al2-C109 2.034(3), N6-C109 1.279(4), C109-C110 1.535(3), C110-O5 1.306(4), C110-O6 1.233(5), K1-O5 2.914(2), K1-O6 2.714(3).

To gain a better understanding of the electronic structure of $\mathbf{4}$, the isolated [(NON)AINDipp] ion was investigated by DFT calculations at the PBE1PBE/Def-TZVP level. The calculated and experimentally determined structural metrics are in very good agreement. The HOMO and HOMO-1 (at -1.27 and -2.25 eV) represent a pair of orthogonal nitrogen-centred $p$ orbitals with very little contribution from aluminium. The Wiberg Bond Index (WBI) for the Al-N bond is calculated to be 0.705 , and the associated Mulliken charges $+0.67(\mathrm{Al})$ and $-0.16(\mathrm{~N})$, consistent with a description as a highly polarised sigma bond. The negative charge at $\mathrm{N}$ is partially mitigated by delocalisation into the adjacent phenyl $\pi$ system, as supported by a WBI of 1.356 for the $\mathrm{N}-\mathrm{C}$ bond.

Given the high level of reactivity implied for silyl-substituted imide species by facile onward conversion to $\mathbf{2}$ and $\mathbf{3}$ (Scheme $\mathbf{1}$ ), and the fact that other highly polarised M-E bonds (such as those found in early transition metal imides ${ }^{[15,16]}$ Cui's neutral aluminium imide, ${ }^{[9]}$ and our recently reported aluminium oxide ${ }^{[8 \mathrm{~d}]}$ ) are known to be reactive towards small molecules and $\mathrm{E}-\mathrm{H}$ bonds, we set out to probe the corresponding reactivity of $\mathbf{4}$. While $\mathbf{4}$ is indefinitely stable in toluene solution at room temperature and does not undergo further reaction with $\mathrm{Me}_{3} \mathrm{SiN}_{3}$ or $\mathrm{DippN} \mathrm{N}_{3}$, it activates dihydrogen in 1,2-fashion. Thus, heating a solution of 4 under an atmosphere of $\mathrm{H}_{2}$ for $14 \mathrm{~h}$ at $80{ }^{\circ} \mathrm{C}$, leads to the formation of (amido)aluminium hydride complex 5 via addition of $\mathrm{H}_{2}$ across the Al-N bond (Scheme 2, Figure 2 and ESI). Unlike the reaction with the corresponding aluminium oxide, the reaction in the case of imide 4 requires heating, ${ }^{[8 \mathrm{~d}]}$ presumably due to the increased

For internal use, please do not delete. Submitted_Manuscript 
steric shielding of the basic $\mathrm{N}$ centre, and partial deocalization of negative charge into the aryl $\pi$ system of the Dipp substituent.

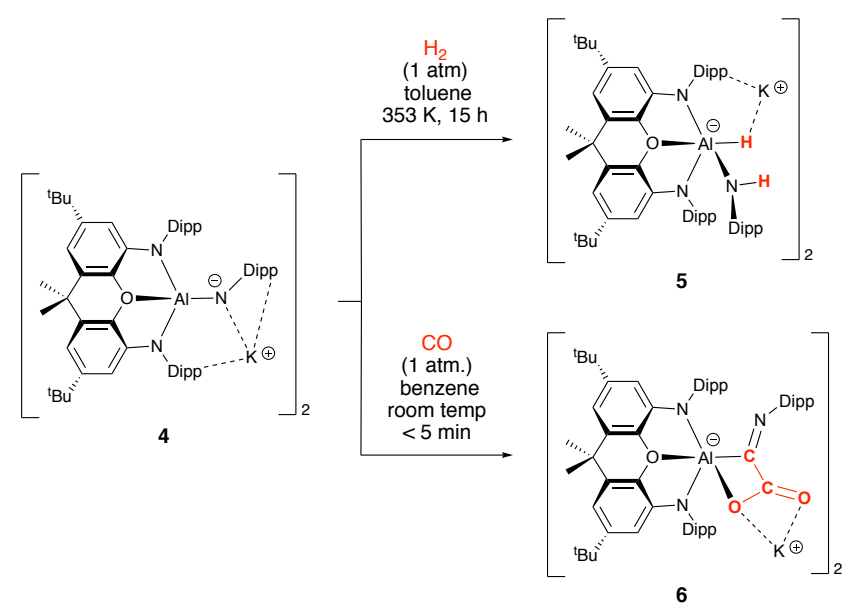

Scheme 2. Reactivity of aluminium imide complex 4 with $\mathrm{H}_{2}$ and CO.

Most interestingly, $\mathbf{4}$ is found to react with $\mathrm{CO}$ via a transformation which proceeds via $\mathrm{C} \equiv \mathrm{O}$ bond cleavage and $\mathrm{C}-\mathrm{C}$ bond formation. Thus, exposure of a benzene solution 4 to an atmosphere of $\mathrm{CO}$ leads to an immediate colour change from colourless to orange and quantitative conversion (by in situ ${ }^{1} \mathrm{H}$ and ${ }^{13} \mathrm{C}$ NMR monitoring) to a single new species which can then be isolated in ca. $50 \%$ yield. The identity of the product (6) is unambiguously revealed through single crystal X-ray diffraction studies, to be derived from assimilation of two molecules of $\mathrm{CO}$, and to feature an unprecedented $\left[(\mathrm{DippN}) \mathrm{CCO}_{2}\right]^{2-}$ fragment bound in $\kappa^{2}(\mathrm{O}, \mathrm{C})$ fashion to aluminium (Scheme 2 and Figure 2).
The asymmetric unit is comprised of two crystallographically independent [(NON)Al\{(DippN) $\left.\left.\mathrm{CCO}_{2}\right\}\right]^{-}$units bridged by $\mathrm{K}^{+}$ counter ions to form a dinuclear aggregate, which also features a benzene molecule coordinated to $\mathrm{K} 1$. The $\mathrm{C}-\mathrm{O}$ bond lengths within the $\left[(\mathrm{DippN}) \mathrm{CCO}_{2}\right]^{2-}$ fragment [e.g. $d(\mathrm{C} 110-\mathrm{O} 5)=1.306(4)$ $\AA ; d(C 110-\mathrm{O} 6)=1.233(5) \AA]$ are indicative of a carboxylate group bound through $\mathrm{O} 5$ at $\mathrm{Al} 2$, and via predominantly electrostatic interactions at $\mathrm{K} 1$. The exocyclic $\mathrm{C}-\mathrm{N}$ bond length $[d(\mathrm{C} 109-\mathrm{N} 6)=$ $1.279(4) \AA]$, is consistent with a formulation incorporating a $C=N$ double bond, while the $C 109-C 110$ distance $[1.535(3) \AA]$ is indicative of a $\mathrm{C}-\mathrm{C}$ single bond formed by coupling two molecules of CO. ${ }^{[14]}$

The conversion of $\mathbf{4}$ to $\mathbf{6}$ via the uptake of two molecules of $\mathrm{CO}$ has been investigated by quantum chemical and experimental methods (Figure 3 and Scheme 3). A mechanism is proposed involving initial end-on approach of the first $\mathrm{CO}$ molecule leading to the formation of an intermediate (Int-1) featuring an AINC threemembered ring. ${ }^{[17]}$ Alternatively, this species could be viewed as involving side-on binding of a DippNCO isocyanate moiety at aluminium via the $\mathrm{CN} \pi$ bond. Isomerization via the ratedetermining transition state (lying $98.9 \mathrm{~kJ} \mathrm{~mol}^{-1}$ above Int-1) generates a second intermediate, Int-2, which is stabilized by $42.1 \mathrm{~kJ} \mathrm{~mol}^{-1}$ (relative to Int-1), and which can be viewed as an alternative isomeric form in which the DippNCO moiety is now bound via the $\mathrm{CO} \pi$ bond. Sequential lengthening of the $\mathrm{C}-\mathrm{O}$ distance is observed on going from free CO $(1.128 \AA)$ to Int-1 $(1.223 \AA)$ to Int-2 $(1.365 \AA)$, reflecting decreased bond order on the pathway (ultimately) to CO bond breakage. Crucially, given the presence of the DippNCO moiety with both proposed intermediates Int-1 and Int-2, we find that the reaction of aluminyl complex 1 with DippNCO in the presence of $\mathrm{CO}$ leads to the formation of the same final product (6) in good yield.
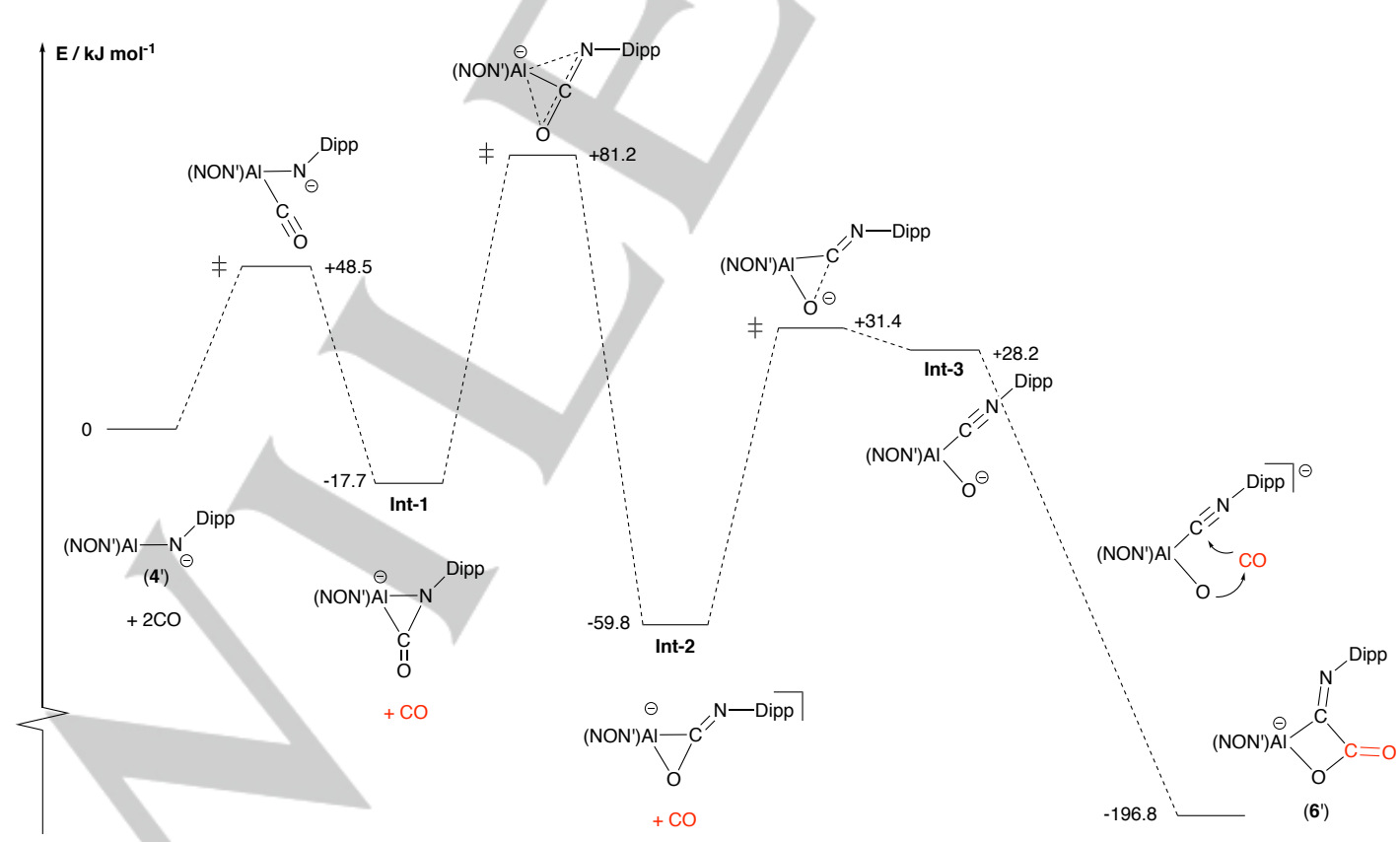

Figure 3. Proposed mechanism based on DFT calculations for the assimilation of two molecules of CO by $\mathbf{4}^{\prime}$ to give $\mathbf{6}^{\prime}$ via $\mathrm{C}$-O bond cleavage and $\mathrm{C}$-C bond formation. For computational efficiency the backbone 'Bu groups of the NON ligand were replaced by methyl groups in all calculations. The 'cut-down' versions of compounds 4 and $\mathbf{6}$ so modeled are labeled $\mathbf{4}^{\prime}$ and $\mathbf{6}$ '.

For internal use, please do not delete. Submitted_Manuscript 
From Int-2 C-O bond cleavage proceeds (via a transition state $91.2 \mathrm{~kJ} \mathrm{~mol}^{-1}$ higher in energy) to generate a highly reactive intermediate species Int-3 which can be regarded as a DippNC adduct of the aluminium oxide [(NON')AlO] ${ }^{-}$. Assimilation of $\mathrm{CO}$ then occurs to yield $\mathbf{6}^{\mathbf{}}$ via an essentially barrierless process which relies on the nucleophilic nature of the oxide moiety and the electrophilic nature of the Al-bound isonitrile carbon atom. Given the experimental availability of the related aluminium oxide thf adduct, $\mathrm{K}_{2}[(\mathrm{NON}) \mathrm{AlO} \text { (thf) }]_{2}(7),{ }^{\left[{ }^{[\mathrm{d}]}\right]}$ further evidence for the viability of this last mechanistic step could be obtained from the reaction of 7 with excess xylyl isonitrile, XyINC. This process leads to the uptake of two molecules of XyINC to generate compound 8 (Scheme 3 and ESI) which has a structure analogous to 6 in which the $\mathrm{C}=\mathrm{O}$ unit has formally been replaced by $\mathrm{C}=\mathrm{NXyl}$.
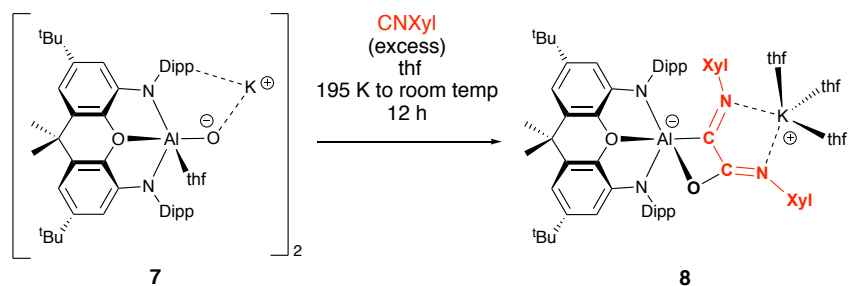

Scheme 3. Experimental reactivity relevant to the proposed mechanism for the formation of $\mathbf{6}$ from 4 : reaction of aluminium oxide complex 7 with xylyl isonitrile.

In summary, we find that anionic imide complexes of aluminium are accessible via a logical synthetic approach involving the reactions of organo azides with an aluminyl precursor. The resulting highly polar Al-N unit is capable of the activation of very strong chemical bonds, such as those found in $\mathrm{H}_{2}$ and $\mathrm{CO}$, leading in the latter case to $\mathrm{C}-\mathrm{C}$ coupling in addition to $\mathrm{C} \equiv \mathrm{O}$ bond cleavage. This process appears to be driven (at least in part) by the thermodynamic incentive of $\mathrm{Al}-\mathrm{O}$ bond formation, and to proceed via a mechanism which involves exchange of the $\mathrm{NR}$ and $\mathrm{O}$ substituents via intermediates featuring an aluminiumbound isocyanate fragment.

\section{Acknowledgements}

We thank the Leverhulme Trust (F/08699/E) for funding aspects of this work. PV thanks the Academy of Finland (Grant No. 314794).

Keywords: aluminium $\bullet$ imide $\cdot$ aluminyl $\bullet$ carbon monoxide $\bullet$ small molecule activation

[1] a) Advances in Fischer-Tropsch Synthesis Catalysts and Catalysis, B. H. Davis, M. L. Occelli, Eds., CRC, Boca Raton, FL, 2009; b) A. Y. Khodakov, W. Chu, P. Fongarland, Chem. Rev. 2007, 107, 1692-1744. (c) C. K. Rofer-DePoorter, Chem. Rev. 1981, 81, 447-474. (d) C. Masters, Adv. Organomet. Chem. 1979, 17, 61-103.

[2] s-Block: a) L. Gmelin, Ann. Phys. Chem. 1825, 4, 31-62; b) W. Büchner, Helv. Chim. Acta 1963, 46, 2111-2120; c) S. Coluccia, E. Garrone, E. Guglielminotti, A. Zecchina, J. Chem. Soc., Faraday Trans. 11981, 177, 1063-1073; d) P. W. Lednor, P. C. Versloot, J. Chem. Soc. Chem. Commun. 1983, 284-285; e) R. Lalrempuia, C. E. Kefalidis, S. J. Bonyhady, B. Schwarze, L. Maron, A. Stasch, C. Jones, J. Am. Chem. Soc. 2015, 137, 8944-8947; f) M. D. Anker, M. S. Hill, J. P. Lowe, M. F. Mahon, Angew. Chem., Int. Ed. 2015, 54, 10009-10011.
[3] d-Block: a) P. A. Bianconi, I. D. Williams, M. P. Engeler, S. J. Lippard, J. Am. Chem. Soc. 1986, 108, 311-313; b) P. A. Bianconi, R. N. Vrtis, C. P. Rao, I. D. Williams, M. P. Engeler, S. J. Lippard, Organometallics 1987, 6, 1968-1977; c) R. N. Vrtis, C. P. Rao, S. G. Bott, S.J. Lippard, J. Am. Chem. Soc. 1988, 110, 7564-7566; d) J. D. Protasiewicz, S. J. Lippard, J. Am. Chem. Soc. 1991, 113, 6564-6570; e) E. M. Carnahan, J. D. Protasiewicz, S. J. Lippard, Acc. Chem. Res. 1993, 26, 90-97; f) A. J. M. Miller, J. A. Labinger, J. E. Bercaw, J. Am. Chem. Soc. 2008, 130, 1187411875; g) T. Watanabe, Y. Ishida, T. Matsuo, H. Kawaguchi, J. Am. Chem. Soc. 2009, 131, 3474-3475.

[4] f-Block: a) W. J. Evans, J. W. Grate, L. A. Hughes, H. Zhang, J. L. Atwood, J. Am. Chem. Soc. 1985, 107, 3728-3730; b) O. T. Summerscales, F. G. N. Cloke, P. B. Hitchcock, J. C. Green, N. Hazari, Science 2006, 311, 829-831; c) O. T. Summerscales, F. G. N. Cloke, P. B. Hitchcock, J. C. Green, N. Hazari, J. Am. Chem. Soc. 2006, 128, 9602-9603; d) W. J. Evans, D. S. Lee, J. W. Ziller, N. Kaltsoyannis, J. Am. Chem. Soc. 2006, 128, 14176-14184; e) A. S. Frey, F. G. N Cloke, P. B. Hitchcock, I. J. Day, J. C. Green, G. Aitken, J. Am. Chem. Soc. 2008, 130, 13816-13817; f) P. L. Arnold, Z. R. Turner, R. M. Bellabarba, R. P. Tooze, Chem. Sci. 2011, 2, 77-79; g) S. M. Mansell, N. Kaltsoyannis, P. L. Arnold, J. Am. Chem. Soc. 2011, 133, 9036-9051; h) B. M. Gardner, J. C. Stewart, A. L. Davis, J. McMaster, W. Lewis, A. J. Blake, S. T. Liddle, Proc. Natl. Acad. Sci. U. S. A. 2012, 109, 9265-9270; i) B. Wang, G. Luo, M. Nishiura, Y. Luo, Z. Hou, J. Am. Chem. Soc. 2017, 139, 16967-16973.

[5] p-Block: a) H. Braunschweig, T. Dellermann, R. D. Dewhurst, W. C. Ewing, K. Hammond, J. O. C. Jimenez-Halla, T. Kramer, I. Krummenacher, J. Mies, A. K. Phukan, A. Vargas, Nature Chem. 2013, 5, 1025-1028. See also ref 4i and b) X. P. Wang, Z. L. Zhu, Y. Peng, H. Lei, J. C. Fettinger, P. P. Power, J. Am. Chem. Soc. 2009, 131, 69126913; c) Z. D. Brown, P. P. Power, Inorg. Chem. 2013, 52, 6248-6259; d) R.Y. Kong, M.R. Crimmin, J. Am. Chem. Soc. 2018, 140, 13614-13617 (mixed p/d-block); e) A. V. Protchenko, P. Vasko, D. C. H Do, J. Hicks, M. A. Fuentes, C. Jones, S. Aldridge, Angew. Chem. Int. Ed. 2019, 58, 1808-1812.

[6] Two-centre reduction of $\mathrm{CO}$ by boron/phosphorus frustrated Lewis pairs has been reported: a) M. Sajid, L.-M. Elmer, C. Rosorius, C. G. Daniliuc, S. Grimme, G. Kehr, G. Erker, Angew. Chem., Int. Ed. 2013, 52, 22432246; b) R. Dobrovetsky, D. W. Stephan, J. Am. Chem. Soc. 2013, 135, 4974-4977; c) M. Devillard, B. de Bruin, M. I. Siegler, J. I. van der Vlugt, Chem.-Eur. J. 2017, 23, 13628. See also: d) M. Arrowsmith, J. Böhnke, H. Braunschweig, M. A. Celik, Angew. Chem. Int. Ed. 2017, 56, 1428714292; e) H. Wang, L. Wu, Z. Lin, Z. Xie, Angew. Chem. Int Ed. 2018, 57, 8708-8713.

[7] a) M. Majundar, I. Omlor, C. B. Yildiz, A. Azizoglu, V. Huch, D. Scheschekewitz, Angew. Chem. Int Ed. 2015, 54, 8746-8750; b) Y. Wang, A. Kostenko, T. J. Hadlington, M.-P. Luecke, S. Yao, M. Driess, J, Am. Chem. Soc. 2019, 141, 626-634; c) Y. Xiong, S. Yao, T. Szilvási, A. Ruzicka, M. Driess, Chem.Commun. 2020, 56 ,747-750.

[8] a) J. Hicks, P. Vasko, J. M. Goicoechea, S. Aldridge, Nature, 2018, 557, 92-95; b) J. Hicks, A. Mansikkamäki, P. Vasko, J. M. Goicoechea, S. Aldridge, Nat. Chem. 2019, 11, 237-241; c) J. Hicks, P. Vasko, J. M. Goicoechea, S. Aldridge, J. Am. Chem. Soc. 2019, 141, 11000-11003; d) J. Hicks, A. Heilmann, P. Vasko, J. M. Goicoechea, S. Aldridge, Angew, Chem. Int. Ed. 2019, 58, 17265-17268.

[9] (a) J. Li, X. Li, W. Huang, H. Hu, J. Zhang, C. Cui, Chem. Eur. J. 2012, $18,15263-15267$. During the final stages of revision of this manuscript, a related aluminium imide synthesis was reported: (b) M. D. Anker, R. J. Schwamm, M. P. Coles, Chem. Commun. in press (DOI: 10.1039/ C9CC09214E).

[10] D. W. Stephan, G. Erker, Angew. Chem. Int. Ed. 2015, 54, 6400-6441.

[11] a) N. J. Hardman, C. Cui, H. W. Roesky, W. H. Fink, P. P. Power, Angew. Chem. Int. Ed. 2001, 40, 2172-2174. See also: b) C. Cui, H. W. Roesky, H.-G. Schmidt, M. Noltemeyer, Angew. Chem. Int. Ed. 2000, 39, 45314533. See also: c) H. Zhu, J. Chai, V. Chandrasekhar, H. W. Roesky, J. Magull, D. Vidovic, H.-G. Schmidt, M. Noltemeyer, P. P. Power, W. A. Merrill, J. Am. Chem. Soc. 2004, 126, 9472-9473; d) H. Zhu, Z. Yang, J.

For internal use, please do not delete. Submitted_Manuscript 
Magull, H. W. Roesky, H.-G. Schmidt, M. Noltemeyer, Organometallics 2005, 24, 6420-6425.

[12] M. D. Anker, M. Lein, M. P. Coles, Chem. Sci. 2019, 10, 1212-1218.

[13] M. D. Anker, M. P. Coles, Angew. Chem. Int. Ed. 2019, 58, 18261-18265

[14] B. Cordero, V. Gómez, A. E. Platero-Prats, M. Revés, J. Echeverría, E. Cremades, F. Barragán, S. Alvarez, Dalton Trans. 2008, 2832-2838.

[15] Recent examples of $\mathrm{H}_{2}$ activation by early transition metal imides include: a) X. Han, L. Xiang, C. A. Lamsfus, W. Mao, E. Lu, L. Maron, X. Leng, Y. Chen, Chem. Eur. J. 2017, 23, 14728-14732; b) H. S. la Pierre, J. Arnold, F. D. Toste, Angew. Chem. Int. Ed. 2011, 50, 3900-3903; c) A. M. Geer, C. Tejel, J. A. López, M. A. Ciriano, Angew. Chem. Int. Ed. 2014, 53, 5614-5618.
[16] For a review of C-H activation by early transition metal imides, see: P. T. Wolczanski, Organometallics, 2018, 37, 505-516.

[17] For a previous report of an aluminium carbonyl complex see: a) A. J. Hinchcliffe, J. S. Ogden, D. D. Oswald, J. Chem. Soc., Chem. Commun. 1972, 338-339. For examples of isolable compounds featuring coordination of the $\mathrm{CO}$ molecule to a group 13 element centre, see: b) F. Dahcheh, D. Martin, D. W. Stephan, G. Bertrand, Angew. Chem. Int. Ed. 2014, 53, 13159-13163; c) H. Braunschweig, R. D. Dewhurst, F. Hupp, M. Nutz, K. Radacki, C. W. Tate, A. Vargas, Q. Ye, Nature, 2015, 522, 327-330.

For internal use, please do not delete. Submitted_Manuscript 
WILEY-VCH

\section{Entry for the Table of Contents}

\section{COMMUNICATION}

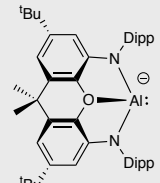

'Bü

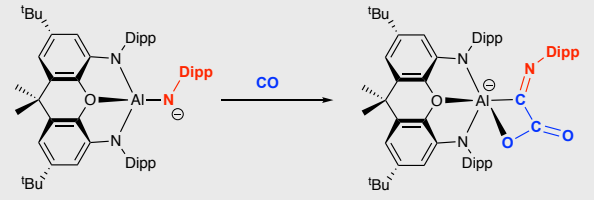

C-C-Coupling: An isolable molecular aluminium imide with a highly polarised $\mathrm{Al}-\mathrm{N}$ bond has been found to react with $\mathrm{CO}$ via $\mathrm{C}-\mathrm{O}$ bond cleavage and $\mathrm{C}-\mathrm{C}$ coupling.
Andreas Heilmann, Jamie Hicks, Petra Vasko, Jose M. Goicoechea*, Simon Aldridge*

Page No. - Page No.

Carbon Monoxide Activation by a Molecular Aluminium Imide: $\mathrm{C}-\mathrm{O}$ Bond Cleavage and C-C Bond Formation

For internal use, please do not delete. Submitted_Manuscript 